\title{
Hot Flashes, CTCAE
}

National Cancer Institute

\section{Source}

National Cancer Institute. Hot Flashes, CT CAE. NCI Thesaurus. Code C143549.

A disorder characterized by an uncomfortable and temporary sensation of intense body warmth, flushing, sometimes accompanied by sweating upon cooling. 